\title{
An overview of Scheuchzeria palustris in Scotland and a new locality in Westerness (v.c.97)
}

\author{
Paul A. Smith ${ }^{1 *}$, Ian M. Strachan ${ }^{2}$ Andrew M. Coupar ${ }^{3}$ \\ ${ }^{1}$ University of Southampton, England; ${ }^{2}$ Invernesshire, Scotland; ${ }^{3}$ NatureScot, \\ Golspie, Scotland
}

*Corresponding author: Paul A. Smith: p.a.smith@soton.ac.uk

This pdf constitutes the Version of Record published on $16^{\text {th }}$ February 2021

\begin{abstract}
A new locality for Scheuchzeria palustris L. (Rannoch Rush) in Westerness extends its extant range in Scotland. The characteristics of the site are presented in the context of the known distribution and ecology of $S$. palustris on and around Rannoch Moor, the only extant populations in the British Isles. An overview of the population dynamics revealed by monitoring since 1988 is given.
\end{abstract}

Keywords: distribution; monitoring; vegetation community; insect interactions.

\section{Introduction}

In the British Isles Scheuchzeria palustris L. (Rannoch-rush) is a rare and shyflowering species of acid moorland, known recently only from Scotland, although formerly found in England and Ireland too. Scarth (1911) suggests that by 1910, when it was discovered on Rannoch Moor, S. palustris was already extinct at all the sites in Britain where it had previously been recorded, including Methven Moss near Perth, the site where it was first discovered in Scotland in 1833. A combination of a change in hydrology and over-collection probably led to its extinction at Methven. Sledge (1949) gives a comprehensive assessment of the historical records for this species in Britain, and the Irish population at Pollagh Bog (v.c.H18), whose discovery post-dated his paper, was described in detail by Moore (1955); however, it became extinct in this location too not many years later (Tallis \& Birks, 1965, Rumsey, 2002).

Rodwell et al. (1991) give $S$. palustris only as a rare component of the M1 plant community (Sphagnum auriculatum bog pool community), but Tallis \& Birks (1965) suggest that it occurs over a wide range of trophic levels elsewhere in Europe. The community of the British and Irish populations probably does not represent the full range of associations.

\section{Rannoch Moor}

In Scotland S. palustris has been found since 1910 only in the area around Rannoch Moor (vice-counties 88, 97 \& 98). Sledge (1949) found it be widespread away from the usual populations near the railway station where most botanists stopped to see it, with scattered locations over the moorland. Recent records are in three principal clusters. One is around Lochan a' Chlaidheimh (NN46A), which Sledge identified as the original location found in 1910. A more widespread cluster of sites is to the 
south-east of Loch Laidon (mainly NN45), and a third is further west, centred around Lochan Gaineamhach (generally north and east of the A82).

AMC surveyed the vegetation of Rannoch Moor in 1988 (Coupar, 1989), and recorded populations of notable plant species, including S. palustris, although not comprehensively. He found from several to thousands of stems in 44 locations (though it is likely that these are not really separate populations, but form one or more metapopulations). Most of the locations conformed with the NVC M1 community (Rodwell et al., 1991), and the associates were generally a combination of Sphagnum denticulatum, S. cuspidatum, Carex lasiocarpa, C. limosa, C. rostrata, Eriophorum angustifolium, Menyanthes trifoliata, and in one site each also with Carex pauciflora and Equisetum fluviatile. There were some interesting sites with different characteristics. One was the terminal pool of a small stream, which was more nutrient rich than the characteristic M1 sites, and here the associates included Potamogeton polygonifolius and Juncus bulbosus. A further location was on the undercut margin of a lochan, with the marginal vegetation formed by Sphagnum papillosum and S. cuspidatum. Finally one site was in an area that had been considerably disturbed by burning and grazing, a situation which might be expected to lead to local die-out; here the associates included Molinia caerulea, Myrica gale and Potamogeton polygonifolius in addition to the more usual Eriophorum angustifolium, Carex limosa and Sphagnum denticulatum. So it seems that $S$. palustris can persist in a wider range of communities than just M1, and this makes its restricted distribution even harder to explain.

Site condition monitoring (SCM) of Rannoch Moor has followed Coupar's (1989) locations when surveying $S$. palustris, recent reports give quite specific counts from 1988 which are not in Coupar (1989), and we suspect they may have been constructed from phrases in the report and gathered an unwarranted legitimacy. Nonetheless, we use them below as indicative of population sizes. SCM counts have been of flowering stems, whereas Coupar's counts were of stems, which also suggests some mismatch of numbers. In 2002 SCM also found that $S$. palustris occurred in two vegetation types, with most stands in M1 (though avoiding the most acidic facies), but also in M17a (Trichophorum cespitosum-Eriophorum vaginatum mire, Drosera-Sphagnum spp. sub-community) (Loizou, 2003).

The 2002 SCM survey failed to find S. palustris in only one of the sites from the 1988 survey, and found several new sites. It was followed with counts from three populations in 2008, and a further SCM survey in 2013 (Haycock and Jay Associates Ltd, 2014), which similarly refound $S$. palustris in almost all the previous locations and added several further new ones. The accumulation of new locations on Rannoch Moor suggests that there are further sites to be found with a comprehensive survey.

Table 1 gives summary information on the counts from the 1988, 2003 and 2013 surveys. The variation in time of year and the counting of all shoots vs flowering shoots makes it difficult to interpret the trends, but there does seem to have been a substantial increase in numbers of shoots compared with 1988 (even accounting for numbers constructed post hoc). It is clear that 1988 had much lower counts than the subsequent surveys, though whether the time of year of counting has an important effect is unclear. 
Table 1. Totals of counts of shoots $(1988,2002)$ and flower spikes (2013) from site condition monitoring of Scheuchzeria palustris on Rannoch Moor. *Consistent counts covering only sites covered in all three surveys.

\begin{tabular}{|l|c|c|}
\hline survey period & $\begin{array}{c}1988 \text { sites } \\
\text { only* }\end{array}$ & all sites \\
\hline 1988, Oct & 27,082 & 27,082 \\
2002, Jul-Aug & 68,992 & 130,454 \\
2013, Jun & 57,160 & 130,140 \\
\hline
\end{tabular}

The locations newly identified in 2002 and 2013 have included some large populations, with several with counts of $\geq 10,000$, and this shows the difficulty in surveying for this species. Whether these sites have been bypassed by chance during surveys, or whether they have become more conspicuous because of the number of shoots at the survey times is not clear. It is, however, instructive to examine the pattern of counts for traceable populations with consistent grid references; one site has counts of 12,30 and 4,000, and another has 3,000,11,000 and 3,000. One site first discovered in 2002 went from 20,000 to 3,300 shoots. The grid references for several sites have varied between 2002 and 2013, which seems to indicate that shoots may appear locally in response to changes in conditions (perhaps with rhizomes remaining in place and able to react to further changes in the future?). It seems that a longer series of monitoring counts will be needed to deduce the dynamics and long-term trends of these populations. The possibility that the species is temporarily not detectable should also be considered in longer-term monitoring; one site showed a count pattern of 35, 0,500. Anecdotal evidence from specific surveys known to IMS and AMC also suggests that $S$. palustris can be difficult to find at known sites in some years.

There are also some outlying records which are not part of the three main clusters. The BSBI Scottish recording week based at Corrour in 2009 found a new location for S. palustris, more than $2 \mathrm{~km}$ from the known ones, and north of the Blackwater reservoir (NN36L). A second outlier discovered in 2003 several km to the east (NN46W), as well as being the easternmost outlier is also at a substantially higher altitude than the Rannoch Moor populations (which are all around $300 \mathrm{~m}$ ), at $390 \mathrm{~m}$. A further outlier in NN44E was recorded in 1981 in an area which is now marked as forestry on the OS Map; it may be worth searching this area further to see if a remnant has survived. These outlying localities suggest that there may be still further places around Rannoch where $S$. palustris grows, awaiting discovery.

\section{A new locality}

On 14 July 2018, during the Scottish recording week based at Kingie, PAS, IMS and Gordon Rothero recorded up the Alt Daingean into an area of Coire Daingean. In an area of pools and peaty runnels at NH24270555 S. palustris was discovered (Fig. 1); 44 fruiting spikes were present in an area around $40 \times 20 \mathrm{~m}$, mostly along the edges of the bare peaty runnels ('soaks' in the sense of Tallis \& Birks, 1965). These were rather dry, although the weather had been dry in summer 2018, and this may not have been typical. No specimens were found in or near the pools of standing water that were also present. 


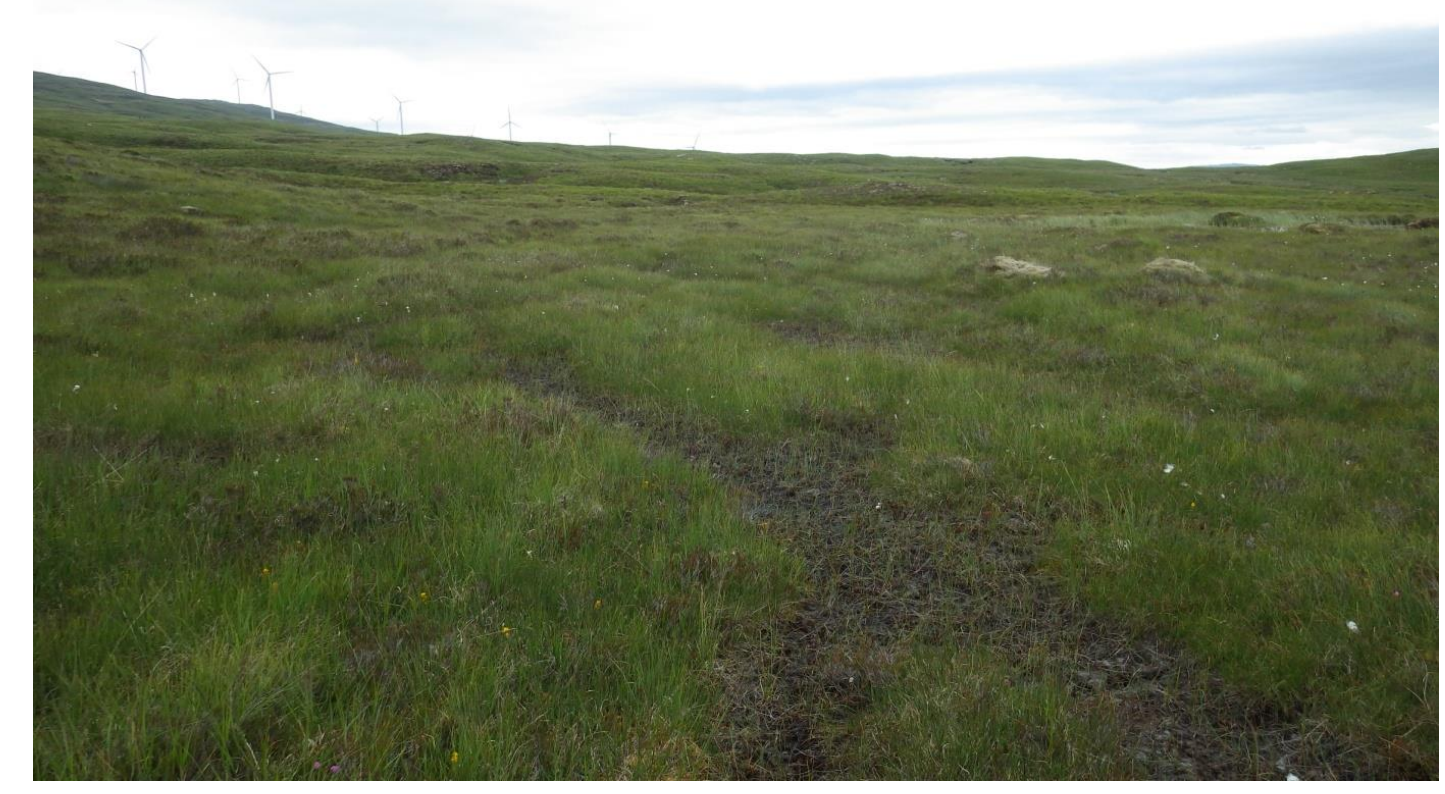

\section{Figure 1. Habitat of Scheuchzeria palustris at Coire Daingean, 14 July 2018, showing the proximity of the Millennium wind farm to the north-east (Ian Strachan).}

Sledge (1949) commented that $S$. palustris was almost never found without Carex limosa, and indeed that species was quite frequent in the area. The uncommon Sphagnum austinii was also found nearby. So this was an example of a poor-fen habitat for this species. The runnels were also largely bare of Sphagnum, whereas in many other locations $S$. palustris is found growing in a mat of Sphagnum spp (Sledge 1949, Moore 1955, Rodwell et al. 1991), so it was not possible to assign these communities to M1 or M2 of the NVC.

The locality at Coire Daingean is near to two wind farms; it lies between the Millennium Wind Farm constructed 2006-11 lying to the north-east (Fig. 1), and the more recent Beinneun Wind Farm constructed 2015-17 and lying to the north-west (BEIS 2020). However, it is apparently sufficiently distant not to be affected by the construction, as long as the hydrology is not modified.

The site is at $460 \mathrm{~m}$ altitude, which is a new upper altitudinal limit for Britain and Ireland. Tallis \& Birks (1965) note that in northern Europe $S$. palustris is a plant of low altitudes which avoids the mountain regions. However, data from GBIF (2018), mostly collected since their paper was written, show that $S$. palustris is frequently recorded at higher altitudes in Norway (as well as many lower ones), with over 150 records at the same altitude as Coire Daingean or higher, up to $1235 \mathrm{~m}$. Therefore this altitude is not unusual in a European context.

\section{Flowering and fruiting}

AMC's survey of Rannoch Moor took place in October and November, and it was possible to see evidence of flowering. There was some anecdotal evidence that larger populations had a higher proportion of shoots flowering; a specific data collection to examine this possibility would contribute to our understanding of the persistence of $S$. palustris and its capacity for spread to new locations. In this respect the Coire Daingean site was unusual, as most of the shoots seen were 
fruiting. Certainly the species is much less conspicuous when it is in small quantity and vegetative.

At one site on Rannoch Moor in October 1988 the many seeds remaining on the plants had a single hole apparently from the activity of an insect (presumably an emergence hole since there was one in each seed), and the seeds were hollow (Coupar 1989). Fig. 2 shows a fruiting shoot from Coire Daingean where one of the fruits has apparently been damaged by insect activity. Only one species, an aphid, is given as feeding on S. palustris in the Database of insects and their food plants (http://www.brc.ac.uk/dbif/homepage.aspx), and this host is not mentioned on the Dutch gall and mines site https://bladmineerders. $\mathrm{nl} /$. So there may be interesting associations to be investigated here too.

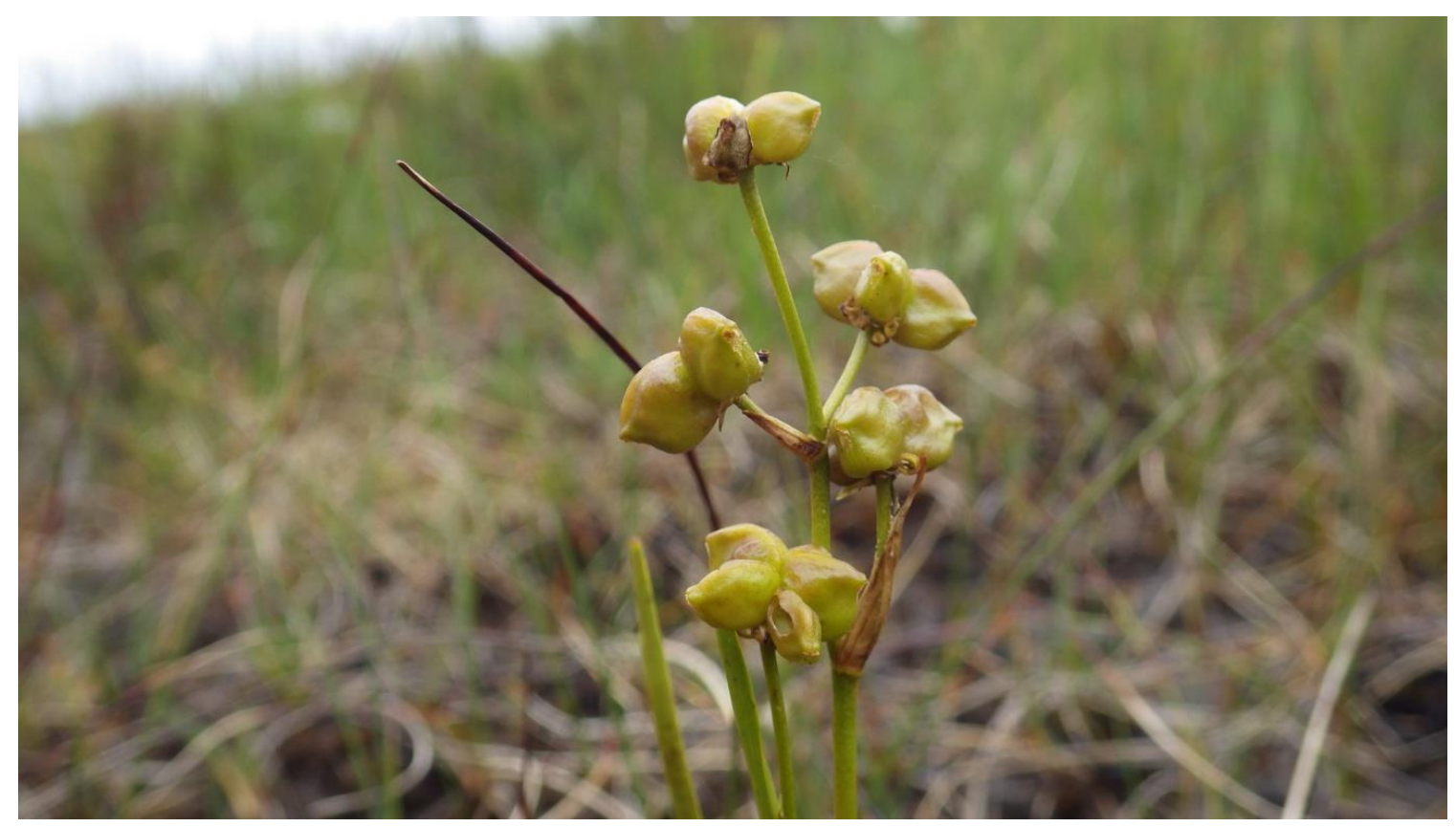

Figure 2. Fruiting stem of Scheuchzeria palustris at Coire Daingean, 14 July 2018. The bottom-most fruit in the picture has apparently been damaged, presumably by insect activity (Ian Strachan).

\section{Discussion}

The new site is north of the Great Glen faultline, which is usually regarded as significant in a biogeographical context. It is also a significant extension of the extant range of $S$. palustris, by approx. $40 \mathrm{~km}$, although the former wider distribution (Sledge 1949, Rumsey 2002, p671) makes this less surprising than it might be if Rannoch Moor had been the only groups of localities. However, the relatively unexceptional habitat (though with some interesting species such as Vaccinium microcarpum and Carex limosa) makes it plausible that there are other populations of this species still to be discovered where the hydrology is suitable, and searches in suitable localities near to the new site would be valuable. Carex limosa, considered to be a very frequent associate of S. palustris (Sledge, 1949), has scattered records in vice-counties 96,97 and 105 which meet near to this new site 
and would be a good indicator of sites for searching (though undoubtedly there are also places where the indicators have not yet been discovered).

It seems that, although there has been monitoring of known populations of $S$. palustris on Rannoch Moor, there has not been a thorough and systematic survey, and therefore further populations may await discovery there too.

Moore (1955) inferred the history of colonisation by $S$. palustris at its single Irish station by examination of subfossil evidence from cores, although with no satisfactory explanation for its occurrence. Tallis \& Birks (1965) review the subfossil finds of $S$. palustris, which extend over most of Britain, and demonstrate that there has been a gradual loss as sites have been subject to succession and human modification. A similar investigation would also be possible at Coire Daingean to assess the history of the species here; the initial presumption is that the population has persisted here over a long period.

\section{Acknowledgements}

We are grateful to Gordon Rothero, Alistair Godfrey and Jim McIntosh for comments on an earlier draft, and to NatureScot for permission to cite the SCM reports.

\section{References}

BEIS 2020. Renewable Energy Planning Database quarterly extract. Available at: https://www.gov.uk/government/publications/renewable-energy-planningdatabase-monthly-extract [accessed 23 July 2020].

Coupar, A.M. 1989. Rannoch Moor vegetation survey. Unpublished report to Nature Conservancy Council, Edinburgh.

GBIF 2018. GBIF occurrence download. Available at: https://doi.org/10.15468/dl.uvoks1 [accessed 25 October 2018].

Haycock and Jay Associates Ltd. 2014. Site Condition Monitoring of vascular plant assemblages on Rannoch Moor SSSI. Scottish Natural Heritage Commissioned Report (ROAME No. F05AC701).

Loizou, T. 2003. Rannoch Moor SSSI: Site Condition Monitoring of rare vascular plants. Unpublished report to Scottish Natural Heritage.

Moore, J.J. 1955. The distribution and ecology of Scheuchzeria palustris on a raised bog in Offaly. The Irish Naturalists' Journal 11: 321-329. https://www.jstor.org/stable/25534339

Rodwell, J.S., Pigott, C.D., Ratcliffe, D.A., Malloch, A.J.C., Birks, H.J.B., Proctor, M.C.F., Shimwell, D.W., Huntley, J.P., Radford, E., Wigginton, M.J. \& Wilkins, P. 1991. British plant communities Vol. 2: Mires and heaths. Cambridge: Cambridge University Press.

Rumsey, F.J. 2002. Scheuchzeria palustris. p671 in Preston, C.D., Pearman, D.A. \& Dines, T.D. New atlas of the British and Irish flora. Oxford: Oxford University Press.

Scarth, G.W. 1911. Scheuchzeria palustris, L. Its occurrence as a British plant, with a fresh record. Notes from the Royal Botanic Garden, Edinburgh 5 (22): 57-60. https://www.biodiversitylibrary.org/item/96820.

Sledge, W.A. 1949. The distribution and ecology of Scheuchzeria palustris L. Watsonia 1: 24-35. http://archive.bsbi.org.uk/Wats1p24.pdf. 
Tallis, J.H. \& Birks, H.J.B. 1965. The past and present distribution of Scheuchzeria palustris L. in Europe. The Journal of Ecology 53: 287-298. https://www.jstor.org/stable/2257976.

Copyright retained by author(s). Published by BSBI under the terms of the Creative Commons Attribution 4.0 International Public License.

ISSN: $2632-4970$

https://doi.org/10.33928/bib.2021.03.058 